\title{
Periodic fluctuations in recruitment success of Atlantic cod
}

\author{
Rindorf, Anna; Cadigan, Noel G.; Howell, Daniel; Eero, Margit; Gislason, Henrik
}

\section{Published in:}

Canadian Journal of Fisheries and Aquatic Sciences

Link to article, DOI:

10.1139/cjfas-2018-0496

Publication date:

2020

Document Version

Peer reviewed version

Link back to DTU Orbit

Citation (APA):

Rindorf, A., Cadigan, N. G., Howell, D., Eero, M., \& Gislason, H. (2020). Periodic fluctuations in recruitment success of Atlantic cod. Canadian Journal of Fisheries and Aquatic Sciences, 77(2), 236-246.

https://doi.org/10.1139/cjfas-2018-0496

\section{General rights}

Copyright and moral rights for the publications made accessible in the public portal are retained by the authors and/or other copyright owners and it is a condition of accessing publications that users recognise and abide by the legal requirements associated with these rights.

- Users may download and print one copy of any publication from the public portal for the purpose of private study or research.

- You may not further distribute the material or use it for any profit-making activity or commercial gain

- You may freely distribute the URL identifying the publication in the public portal 


\section{Periodic fluctuations in recruitment success of Atlantic cod}

2 Anna Rindorf $^{1 *}$, Noel Cadigan ${ }^{2}$, Daniel Howell ${ }^{3}$, Margit Eero ${ }^{1}$, Henrik Gislason ${ }^{1}$,

$3 \quad{ }^{1}$ Technical University of Denmark, National Institute of Aquatic Resources, Kemitorvet 1,

$4 \quad$ DK2800 Lyngby, Denmark.

$5 \quad 2$ Marine Institute of Memorial University of Newfoundland, Centre for Fisheries Ecosystems

6 Research. St. John's, NL, Canada A1C 5R3.

$7 \quad{ }^{3}$ Institute of Marine Research, Postboks 1870 Nordnes, 5817 Bergen, Norway

$8 \quad{ }^{*}$ Corresponding author. Tel. +45 339633 78. Email: ar@aqua.dtu.dk

\section{Abstract}

10 Autocorrelation in recruitment success of fish is frequently reported, but the underlying mechanisms are generally only vaguely alluded to. We analysed recruitment success of cod 21 stocks in the North Atlantic to investigate possible common causes of autocorrelation in recruitment. We found autocorrelation and periodic fluctuations in recruitment success and adult growth in just above half of the stocks considered and investigated six possible underlying mechanisms. With three exceptions, the variations in recruitment success were not significantly related to temperature or growth anomalies, indicating that the variation was not caused by temperature dependent survival or growth dependent spawning products. Further, a link between recruitment and subsequent spawning biomass could not explain the observed recruitment patterns. Slow-growing cod stocks tended to exhibit longer cycles and positive autocorrelations consistent with dilution of predation mortality by adjacent large year classes or age reading errors whereas fast growing cod stocks showed shorter cycles and no significant autocorrelation at lag 1. Both types exhibited significant negative autocorrelations consistent with cannibalism at one or more lags greater than lag 1. 
Key words: Atlantic cod, recruitment, periodic fluctuations, autocorrelation, cannibalism, growth

\section{Introduction}

Periodic fluctuations in the number of recruits per weight of spawning fish occur in numerous exploited fish stocks (Fogarty et al. 2001; Thorson et al. 2014; Ricard et al. 2016). These changes in recruitment success may be generated by a number of processes, including links to climatic conditions, quality of spawning products, predation, cannibalism, or competition. Climatic conditions can potentially influence recruitment success directly or act as a proxy for relevant factors such as food abundance and temperature that impact the growth and survival of juveniles (Beaugrand et al. 2003; Mantzouni and MacKenzie 2010; Drinkwater et al. 2014). Changes in growth conditions can influence the quality and quantity of spawning products (Morgan and Lilly 2006) and through this influence, cyclic growth patterns, generated e.g. by inter cohort competition for food, can potentially introduce cycles in recruitment success (Skjæraasen et al. 2012). Recurrent changes in predation mortality can occur for a variety of reasons; periodic fluctuations in the abundance of alternative prey, limit cycles generated by cannibalism (Bjørnstad et al. 1999; Ricard et al. 2016), or because other individuals of comparable size shelter juveniles from predation (apparent mutualism, Holt 1977). Another possibility is that the link between recruitment and size of subsequent spawning stock biomass (SSB) leads to positive correlations between the recruitment success in a given year and stock size several years later (Gilbert 1997). This may occur when the relationship between SSB and recruitment is weak and recruitment includes occasional spikes as is the case in several stocks of haddock (ICES 2017c). A high recruitment leads to a subsequent high SSB with no change in the following level of recruitment and therefore a 
low number of recruits per spawner when the strong cohort matures. This may lead to cycle lengths that are correlated to the age of $50 \%$ maturity. Spurious positive correlations between adjacent age classes can be introduced by ageing errors (Bradford 1991), as a large age class is misidentified into the two adjacent yearclasses. In addition, there is a general tendency for late maturing stocks to exhibit greater positive autocorrelation in recruitment (Thorson et al. 2014), though the cause of this has not been determined. Identifying the actual causes of significant autocorrelations is necessary for a greater understanding of population regulation in fish stocks and for practical stock management.

The high potential abundance of Atlantic cod (Gadus morhua) throughout the North Atlantic combined with piscivory, cannibalistic behaviour and large adult size makes it a key regulator in the ecosystems it inhabits, and makes it likely that density dependence is an important feature of its ecology. Furthermore, its well-documented population ecology and cannibalism makes cod an ideal case for investigating the possible causes of periodic recruitment patterns. The numerous processes that can generate fluctuations in the recruitment success of cod could affect the occurrence of cycles in a number of stocks systematically. Changes in the occurrence of food and predators are likely to differ from stock to stock, resulting in differences in oscillations between stocks. Similarly, local climatic changes may introduce periodicities (Casini et al. 2009), where the duration of the periods are likely to vary between regions according to e.g. local temperature. In contrast, large-scale changes such as the NAO may lead to cycles with the same approximately 10 year (decadal) wavelength in all regions and significant correlation across stocks (Hurrell 1995; Beaugrand, et al. 2003). Local changes with wavelengths above 5 years are also expected where slow cycles in the abundance of predators such as marine mammals occur. With the exception of NAO related climatic variables, local changes in food (i.e. changes not related to NAO or similar largescale impacts), climatic conditions and predation are expected to produce periodicities of 
variable length with no apparent pattern across stocks. Hence, if fluctuations between stocks are random, it can be a sign of varying local conditions, with short wavelength fluctuations being more likely to result from local variations in feeding conditions and predation by shortlived predators, while longer wavelengths may indicate changes in climate or long lived 77 predator stocks.

Here, we analyse cod recruitment success in order to investigate the occurrence of periodic

fluctuations and identify the underlying causes. We investigate seven different hypotheses: Atlantic.

1. There are no significant periodic patterns in cod recruitment success;

2. Recruitment success of cod is linked to climate;

3. Patterns in the somatic growth of adults generate patterns in recruitment success;

4. The link between recruitment and the subsequent SSB causes negative autocorrelations in recruitment success at the age of maturity;

5. A large year class dilutes the predation mortality of adjacent year classes (apparent mutualism);

6. A large year class decreases the growth and thereby increases the mortality of the subsequent year class (inter-cohort competition);

7. Autocorrelations are introduced by cannibalism.

To test these hypotheses, we perform time series analyses of recruitment success, age at $50 \%$ maturity, annual sea surface temperature and weight at age for 21 cod stocks in the North 


\section{Definitions and hypotheses}

A time series may show both long term and short term periodic changes (Fig. 1).

Recruitment success can respond to large-scale ecosystem changes and often declines when the biomass of spawning fish increases. This may introduce long-term recruitment (20 years) trends (termed 'regime shifts' in Szuwalski et al. 2015). Here, we focus on periodic fluctuations with a wavelength of less than 20 years and detrend the observed time series (Fig. 1a) to derive time series of deviations from the long-term patterns (Fig. 1b). When these detrended time series show cycles (periodicity), the wavelength is given by the number of years between successive peaks (Fig. 1c) and the lag at which the highest negative correlation is observed is the time between a peak and the successive trough, which by definition equals half of the wavelength of symmetric fluctuations.

Local fluctuations in sea surface temperature may impact recruitment success (hypothesis 2, Beaugrand et al 2003; Mantzouni and MacKenzie 2010). In contrast, decadal wavelengths are consistent with recruitment cycles driven by approximately decadal cycles such as NAO (Hurrel 1995). If all stocks show similar periodicities with a wavelength around 10 years, this would indicate a panregional climatic influence on recruitment across stocks, in accordance with the many studies, which have demonstrated climate impacts on fish stocks (Sundby 2000; Beaugrand et al. 2003; Mantzouni and MacKenzie 2010).

In contrast to hypotheses 1 and 2, hypotheses 3 to 7 may result in systematic differences between stocks. Under hypothesis 3, periodicity in weight of spawners affect recruitment success, and accounting for this relationship will eliminate periodicity in recruitment success. Hypothesis 4 expects a match between the age at 50\% maturity of a stock and the lag at which the highest negative correlation in recruitment success occurs (Fig. 2). Hence, we would expect the wavelength to vary between stocks in accordance with the differences in 
age at $50 \%$ maturity between stocks. Hypotheses 5 to 7 are expected to generate short-term autocorrelation. If a large year class dilutes the predation mortality of adjacent year classes (hypothesis 5), recruitment success will show positive autocorrelation in stocks with slow individual growth where there is a considerable overlap in length distribution between ages for younger fish (Fig. 2). For stocks with rapid individual growth, the length overlap between successive cohorts is less or non-existing, and the possibility to 'hide' among members of a different cohort decreases. Therefore, we expect less or no autocorrelation in fast growing stocks. Inter cohort competition (hypothesis 6) will promote negative short-term autocorrelation in weight at age and cohort strength (Fig. 2). Cannibalism (hypothesis 7) also leads to negative autocorrelation in cohort strength (Fig. 2). In both cases, the negative autocorrelation will peak at the lag corresponding to the size difference where the interaction is most important. For cannibalism, the lag at which a negative autocorrelation occurs depends on the time required to reach the size where cannibalism is possible. As the size at which cannibalism occurs varies considerably less across stocks than weight at age (Kikkert 1993; Bogstad et al. 1994; Brander 1995), the negative effect of a large cohort on subsequent cohorts should occur more rapidly in fast growing populations. In stocks with slow somatic growth, the effects of apparent mutualism (hypothesis 5), inter cohort competition (hypothesis 6) and cannibalism (hypothesis 7) may occur simultaneously. If this is the case, large cohorts may be followed by one or a few additional large cohorts as the large cohort acts to shelter the subsequent cohorts from predation by saturating predators (Holt 1977), or by smaller cohorts as inter cohort competition reduces their growth and cannibalism increases their mortality. The expectations for cyclic patterns and autocorrelations are summarised in Table 1. Further, fig. 2 shows an example of the development in recruitment and spawning stock size of a population of fish which become cannibalistic at age 3 and spawn at age 5 with a weight of $1 \mathrm{~kg}$ which individuals then retain hereafter. The random interannual 
recruitment variation multiplied with the underlying development in recruitment in each hypothesis is taken from cod west of Scotland, and does not differ significantly from white noise.

\section{Model input}

The model input used for the analyses came from approved stock assessments (Table 2: recruitment, spawning stock biomass (SSB), age at 50\% maturity and weight at age) and the International Comprehensive Ocean-Atmosphere Data Set (NCAR, 2018). Monthly sea surface temperature from February to June from 1960-2017 was downloaded from NCAR in 1x1 degree resolution and used to calculate the annual mean SST in each of the 21 stock assessment areas. The most recent analytical assessments available were used for biological data, except where substantial changes had occurred in the stock assessment and the time series recently had been shortened. Recruitment was defined as the number of individuals at the earliest ages recorded in the stock assessment and assigned to the year the recruits were spawned (i.e. recruitment at age 2 in 2010 was taken as an indicator of recruitment at age 0 in 2008). We estimated the recruitment per spawning stock biomass unit (R/SSB), dividing recruitment by SSB in the year the cohort was spawned. We used recruits per spawning stock biomass rather than residuals from a stock-recruitment curve to ensure that the autocorrelation effects of the competition or cannibalism, which seem necessary to explain the curvature of most stock recruitment curves, were retained in the time series. The two last years in the time series were removed to ensure that all recruitment estimates were supported by more than 2 years of catch at age data. The age of recruitment used in stock assessments differs across stocks, but usually corresponds to the age when the fish enter the fishery, which often is after the majority of the natural mortality has acted (ICES 2017a). Substantial periodicities in recruitment should however be retained until the entry of the cohort to the fishery and hence the differences in recruitment age used are not expected to preclude the 
analyses, although they may introduce some variability, which could reduce our ability to identify common trends.

Weight at age was derived from the observed mean weight at age in the stock, where this was available, otherwise weight at age in the catch was used (see table 2 for sources). Average weight at age 4 was used as a proxy for stock specific individual growth rate, as data for this age was given in all assessments (Brander 1995; Mantzouni and MacKenzie 2010). Early parts of the time series for some stocks used constant weight at age, and these were removed prior to analysis. Annual growth anomalies were derived as the difference between the observed and the average weight of the age group divided by the standard deviation of the weights in the time series for the particular age group. From these age-specific anomalies, the annual growth anomaly was estimated as the average of anomalies of all age groups except the youngest and two oldest to account for the lower certainty in these poorly sampled age groups in line with Clausen et al. (2018). The exclusion of the second oldest age group ensured that all stocks exhibited consistently increasing weight with age. As cod generally spawn in winter, the annual anomalies were used as indices of growth and growth anomalies in a given year were analysed for their effect on recruitment success in the following year. Age at $50 \%$ maturity was estimated by linear interpolation between the age with the highest average proportion mature $<50 \%$ and the age with the lowest proportion mature $\geq 50 \%$.

\section{Analyses}

Long term effects of e.g. the level of SSB and regime shifts were removed by de-trending the time series of $\ln (\mathrm{R} / \mathrm{SSB})$. The detrending was performed by fitting a polynomial to the time series and conducting all analyses of autocorrelation and periodicity on the residuals. The order of the polynomial was determined by the length of the time series, restricting the number of parameters in the polynomial to one per 10 year of data (i.e. a stock with 45 years 8 
194 of data was de-trended using a $3^{\text {rd }}$ degree polynomial). The polynomials were reduced by removing the highest order terms that were not significant at the 5\% level. These polynomials retained decadal and shorter periodicities in data and avoided the loss of years in both ends of the time series as would be the case if using a moving average or smoothing functions for detrending. Examples of the resulting de-trended series of recruitment success are shown in Fig. 3.

The effect of temperature and weight at age on recruitment success was estimated by simple regression as well as by testing the effect of temperature and weight at age as a linear effect together with the polynomial used to de-trend recruitment success. Both variables were included in the same model.

\section{Periodicity in recruitment success}

All of the time series were tested to determine if they deviated significantly from white noise (Bartlett's test). To determine the wavelengths of cycles in recruitment success, we estimated the dominant wavelength in the data using periodograms (Madsen 2007). Periodograms were estimated from the de-trended recruitment series smoothed by a Quadratic Spectral kernel (Andrews 1991). Preliminary investigations showed that the results were not particularly sensitive to the choice of smoother. Periodograms integrate information from all lags in one measure and were used to derive the dominant wavelength. Autocorrelations were estimated and analysed for lags 1 to 10 to identify significant negative and positive autocorrelations, taking the presence of other autocorrelations into account through backwards elimination. In contrast to where autocorrelations are estimated within assessment models, this type of external estimation is unbiased (Johnson et al. 2016).

Estimated dominant wavelengths of recruitment success were compared to the average weight at age 4 and age at 50\% maturity. All comparisons were performed using a 
generalized linear model with normally distributed residuals (McCullaugh and Nelder 1989). All statistical analyses were performed in $\mathrm{SAS}^{\circledR}$ version 9.4 for Windows ${ }^{\circledR}$ (SAS Institute 2017).

\section{Results}

\section{No significant cyclic patterns in cod recruitment success (H1)}

Thirteen of the 21 cod data series exhibited significant periodicity in recruitment success (white noise probability less than 5\%, Table 3 ) and 12 of the 13 stocks showed significant autocorrelation at lag 1 . The probability of achieving 13 significant periodicities in 21 stocks by type 2 error when each periodicity has a $5 \%$ risk of type 2 error is $<0.0001$ (estimated from the binomial distribution). The length of the time series had a significant impact on the probability of rejecting the hypothesis of white noise: 4 of the 5 stocks with more than 50 years of data showed significant periodicity whereas only 6 of the 10 stocks with less than 40 years of data showed significant periodicity $(\mathrm{P}=0.0061$ of the probability being the same in the two cases), in line with the results of Johnson et al. (2016). Time series length had no significant effect on estimated wavelength $(\mathrm{P}=0.2901)$. Of the eight stocks not showing significant differences from white noise, one showed significant autocorrelation at one or more lags. Hence, the available data did not support hypothesis 1 as a general explanation.

\section{Recruitment success of cod is linked to climate (H2)}

Recruitment success was significantly related to temperature in four of the 21 stocks prior to detrending recruitment success: S. Gulf of St. Lawrence cod (effect of temperature $=-0.46$, $\mathrm{P}=0.0050$ ), Iceland cod (effect of temperature $=0.37, \mathrm{P}=0.0005)$, Irish Sea cod (effect of temperature $=-0.63, \mathrm{P}=0.0001)$ and North Sea cod (effect of temperature $=-0.66, \mathrm{P}<0.0001)$. After detrending, recruitment success of three stocks remained significantly related to temperature: Irish Sea cod (effect of temperature $=-0.63, \mathrm{P}=0.0001$, identical since this stock 
showed no significant trend), Celtic Sea cod (effect of temperature $=-0.82, \mathrm{P}=0.0129)$ and North Sea cod (effect of temperature $=-0.41, \mathrm{P}=0.0038$ ). Plots of the relationships for each stock are in the supplementary material (Fig. S1).

On average, the dominant wavelength for cod recruitment success was 5.2 years $(95 \%$ confidence intervals 3.7 to 6.6 years, Table 3 ). The confidence interval does not include 10 (decadal periodicity) and only two stocks show wavelengths above 10 years. If the probability of obtaining wavelengths above and below 10 is equal (the mode of the distribution is 10 ), the probability of achieving only 2 values above 10 is 0.0001 . The estimated wavelength differed by a factor 11 between stocks and hence, the data did not support hypothesis 2 of a constant wavelength of recruitment success of around 10 years or the hypothesis that a significant effect of temperature caused periodicity in recruitment success.

\section{Patterns in the somatic growth of adults generate patterns in recruitment success} (H3)

There was a significant correlation between weight anomaly and recruitment success in 6 of the stocks (Fig. S2 in the supplementary material). However, three of these correlations were negative and hence not in the expected direction. When analysing the effect of the weight anomaly on the detrended recruitment success, the significant effect of weight anomaly was retained in three of these stocks and two additional stock exhibited a significant effect of weight anomaly. Three of these five effects were significantly negative. Hence, only two of the 21 stocks (N Gulf of St. Lawrence and N Newfoundland) showed a consistent positive effect of weight anomaly, a level not significantly different from that expected by type 2 error alone $(\mathrm{P}=0.0849)$. Hypothesis 3 was thus not supported by the available data. 


\section{The link between recruitment and the subsequent SSB causes negative}

\section{autocorrelations in recruitment success (H4)}

The dominant wavelength of recruitment success was not significantly related to age at $50 \%$ maturity $(\mathrm{P}=0.1196$, Fig. 4a). Hence, hypothesis 4 was not supported by the available data.

\section{Relationship between average weight at age and recruitment periodicity (H5, $\mathrm{H6}$} and H7)

Weight at age 4 was significantly linearly related to the dominant wavelength of recruitment success $\left(\mathrm{P}=0.0068\right.$, correlation $=-0.57$, corresponding to an $\mathrm{r}^{2}$ of 0.33$)$ and a power relationship between weight at age 4 and wavelength explained slightly more (39\%) of the total variation $\left(\mathrm{r}^{2}=0.39, \mathrm{P}=0.0041\right.$, Fig. $\left.4 \mathrm{~b}\right)$. This is consistent with hypotheses 5 to 7 . Of the 21 stocks, 16 showed positive autocorrelations at lag 1 consistent with hypothesis 5 whereas 5 showed negative autocorrelations at lag 1 (Fig. 5). Significant autocorrelation at lag 1 was found in 10 out of the 21 stocks, and this autocorrelation was significantly correlated to weight at age $4(\mathrm{P}=0.0453$, Fig. $4 \mathrm{c})$. The relationship was even stronger when using an exponential relationship ( $\mathrm{P}=0.0025)$. In the autoregressive models, 10 of the 11 significant effects at lag 1 were positive consistent with hypothesis 5 , whereas 12 of the 14 effects significant at lags greater than 1 were negative consistent with hypothesis 7 (Table 4). Hence, positive effects were most likely at lag 1 and negative effects most likely at longer lags, consistent with the fact that cannibalism is most prevalent in larger individuals while apparent mutualism should act only at short lags. Of the 13 stocks that showed significant autocorrelative effects, 12 had negative effects at one or more lags, in 11 of the cases counteracting an initial positive effect at lag 1 (Fig. 5). Hence, the data do not support either of the hypotheses 5 and 7 as being the only explanation, but instead point to a combination of the hypotheses. Hypothesis 6 received comparatively less support as only one stock showed significant negative autocorrelation at lag 1. 


\section{Discussion}

294

Autocorrelation and cyclic patterns in recruitment success occurred in just above half of the stocks. Slow-growing cod stocks tended to exhibit periodicities consistent with decadal cycles while fast-growing cod stocks showed more rapid fluctuations. Both types exhibited negative autocorrelations at one or more lags greater than lag 1. Of the seven hypotheses suggested in the introduction, five are unlikely to determine recruitment patterns for more than a few of the cod stocks in the present analyses. While dominant wavelengths of slowgrowing stocks (weight at age 4 less than $1.5 \mathrm{~kg}$ ) seemed to correspond to the decadal periodicity expected from climatic changes alone, fast-growing stocks (weight at age 4 greater than $1.5 \mathrm{~kg}$ ) had significantly shorter wavelengths. Further, no consistent relationship with local temperature was found, though three of the four stocks with the fastest growth showed a significant decrease in recruitment success with increasing temperature. Hence, the cycles in recruitment success of cod were not consistently linked to local or panregional climatic changes (hypothesis 2). There was no significant correlation between recruitment success and growth, indicating that patterns in somatic growth did not cause cyclic patterns in offspring quality (hypothesis 3). Further, the lack of a clear link between age at $50 \%$ maturity and recruitment lags meant that the hypothesis that the link between recruitment and the subsequent SSB causes negative autocorrelations in recruitment success (hypothesis 4, Gilbert 1997) could also be rejected. Finally, only one of the 21 stocks exhibited significant negative autocorrelation at lag 1, indicating that the hypothesis that a large year class decreases the growth and thereby increases the mortality of the subsequent year class (hypothesis 6, inter-cohort competition) could also be rejected.

Our analyses estimated shorter wavelengths than those of Spencer and Collie (1997) and Szuwalski et al (2015), who reported average wavelengths of 24 and 21 years, respectively. 
However, their methods are expected to result in greater wavelengths in virtually all cases due to differences in methods. Firstly, Spencer and Collie investigated the strongest autocorrelation in total biomass (equivalent to using the lag with the highest value in table 4). Total biomass integrates several recruitment events and is likely to develop slowly between years except in short-lived species (Spencer and Collie 1997). Szuwalski et al. used recruitment directly to determine regime length. For longer lived stocks with a close relationship between recruitment and SSB in the year of spawning, recruitment should show positive autocorrelation as SSB will not vary greatly from one year to the next. Further, Spencer and Collie (1997) examined periodicity after linear detrending, and this removes less of the long term temporal changes than the detrending method used here, leading to greater expected wavelengths.

Interestingly, our results support the theory of cohort resonance (Bjørnstad et al. 2004;

Botsford et al. 2014). As this theory is based on the assumption that recruitment success is constant, it should not result in changes in recruitment success over time, though the absolute recruitment (not recruitment success) should show wavelengths consistent with age at 50\% maturity.

While the present analyses could not confirm hypotheses 1-4 and 6 as determining cyclic recruitment patterns across all cod stocks examined, it is possible that the factors determining cyclic patterns vary between stocks. For some stocks, no significant cycles existed, while for others, significant cycles clearly differed from a decadal pattern. Five stocks exhibited significant cycles with wavelengths compatible with climate induced decadal fluctuations (wavelengths greater than 8: cod in the eastern Baltic, southern Gulf of St. Lawrence, Flemish Cap, Grand banks and Eastern Scotian Shelf). Of these stocks, one exhibits negative autocorrelative effect at lag 2 (eastern Baltic cod), which may indicate that recruitment in this stock is controlled by combined effects of climate and cannibalism. However, this particular 
stock showed no significant relationship between temperature and recruitment success, and hence, other climatic factors would have to be responsible for the periodicity.

Positive autocorrelations at lag 1 and a decreasing wavelength with increasing weight at age are consistent with large year classes diluting the predation mortality of year classes of a similar weight in slow growing stocks (Table 1). All of the ten stocks, which had a weight of less than $1.5 \mathrm{~kg}$ at age 4 showed positive autocorrelations at lag 1. Positive autocorrelations may also be introduced by age reading errors because age reading bias is likely to distribute individuals from strong year classes across adjacent year classes. Comparisons of Norwegian and Russian cod age determinations for Northeast Arctic cod over the time period from 1992 to 2007 revealed disagreement in $23 \%$ of the determinations, but found more disagreement in cold years than in warm years where cod growth was higher (Yaragina et al. 2011), confirming that slow growing individuals are more prone to age reading bias. This effect may thus contribute to the positive short term autocorrelation observed in slow growing stocks. It is not possible with the current data to determine whether the positive autocorrelation of slow growing stocks are a result of NAO effects or of slow growing cod exhibiting apparent mutualism (hypotheses 2 and 5). Determining which of these causes are of greatest importance for slow growing stocks will require a collation of information about the mortality and growth in different life stages. Other local deviations from the general patterns obviously also occur (for example, Iceland cod showed no significant periodicity in recruitment success). Among the 21 cod stocks, there were 12 stocks with significant negative autocorrelative effects at one or more lags, a pattern consistent with cannibalism (hypotheses 7). However, determining whether the level of cannibalism is sufficient to induce cycles of this magnitude requires modelling based on specific knowledge of diet composition, food consumption and abundance of juvenile and cannibalistic fish. Whereas abundance of fish is often part of standard survey designs, the investigation of consumption and diet 
composition unfortunately is not, and hence the majority of stocks will not have this type of information readily available.

The vast majority of the gadoid species include fish among the top three of reported prey items. About $2 / 3$ of all gadoid species are large enough to be potential cannibals after the larval stage and another $1 / 6$ are large enough to be potential cannibals at two trophic levels: medium size fish on newly settled fish and large fish on medium sized fish (e.g. Pacific cod, Atlantic cod and pollock). This means that cannibalism is a potential source of periodicity in most gadoids, and as a result, simply assuming a positive autocorrelation as a prior for all stocks is unlikely to provide an appropriate description (Thorson et al. 2014). Further, including autocorrelation only at lag 1 may provide overly positive expectations to recruitment as the initial positive autocorrelation was generally followed by subsequent negative autocorrelations at greater lags. If the cycles are caused by cannibalistic effects, their persistence at low stock sizes depends on the persistence of the spatial overlap of juveniles and adults, and as a consequence cannibalistic cycles may occur only at high stock sizes. Introducing autocorrelation in recruitment in assessment at low stock size may then introduce an undesirable bias.

The cause and persistence of the recruitment cycles carry serious implications for management. Most short-term forecasts of fishing opportunities assume that the incoming yearclass will be equal to the geometric mean over a long period. However, when a year of poor recruitment success is likely to be followed by several years of low recruitment success in cold water stocks, and spawning stock biomass tends to change slowly, a poor recruitment is likely to be followed by a similar below average recruitment. Assuming that the two are uncorrelated is likely to result in overoptimistic predictions of recovery rates and as a result, excessive levels of fishing after years of low recruitment success. Including autocorrelation in recruitment predictions can potentially improve estimates of short-term stock development 
and hence increase the quality of catch advice (Johnson et al. 2016). Autocorrelation in recruitment success can make the stock either more resilient or more sensitive to fishing depending on the direction it takes, an important factor to include in management strategy evaluations (Punt et al. 2016) and the estimation of reference points such as the fishing mortality expected to provide the maximum sustainable yield. Based on our analyses, we recommend that autocorrelation and cyclic patterns are considered and if found to be significant, incorporated in both short term and long term projections of recruitment.

\section{Acknowledgements}

The research leading to these results has received funding from the European H2020

Programme under grant agreement PANDORA number 289257 (AR, ME) and the European Fisheries and Maritime Fund (33113-B-15-089), Ministry of Environment and Food in Denmark) (HG).

\section{References}

Andrews, D. W. 1991. Heteroskedasticity and autocorrelation consistent covariance matrix estimation. Econometrica: Journal of the Econometric Society, 817-858.

Beaugrand, G., Brander, K. M., Lindley, J. A., Souissi, S., \& Reid, P. C. 2003. Plankton effect on cod recruitment in the North Sea. Nature 426(6967): 661.

Bjørnstad, O. N., Fromentin, J. M., Stenseth, N. C., and Gjøsæter, J. 1999. Cycles and trends in cod populations. P. Natl. Acad. Sci. 96(9): 5066-5071.

Bjørnstad, O. N., Nisbet, R. M., and Fromentin, J. M. 2004. Trends and cohort resonant effects in age-structured populations. J. Anim. Ecol. 73: 1157-1167. 
414 Bogstad, B., Lilly, G. R., Mehl, S., Palsson, O. K., and Stefánsson, G. 1994. Cannibalism and year-class strength in Atlantic cod (Gadus morhua L.) in Arcto-boreal ecosystems (Barents

Sea, Iceland, and eastern Newfoundland). ICES mar. Sci. Symp. 198: 576-599.

Botsford, L.W., Holland, M.D., Field, J.C., and Hastings, A. 2014. Cohort resonance: a significant component of fluctuations in recruitment, egg production, and catch of fished populations. ICES J. Mar. Sci. 71: 2158-2170.

Bradford, M. J. 1991. Effects of ageing errors on recruitment time series estimated from sequential population analysis. Can. J. Fish. Aquat. Sci. 48(4): 555-558.

Brander, K. 1995. The effect of temperature on growth of Atlantic cod (Gadus morhua L.).

ICES J. Mar. Sci. 52: 1-10.

Brassard, C., Gauthier, J., Schwab, P., Le Bris, A., Way, M., and Collier, F. 2016. The Status of the Northern Gulf of St. Lawrence (3Pn, 4RS) Cod Stock (Gadus morhua) in 2014. DFO

Brattey, J., Cadigan, N., Dwyer, K. S., Healey, B. P., Ings, D. W., Lee, E. M., Maddock

Parsons, D., Morgan, M. J., Regular, P., and Rideout, R. M. 2018. Assessment of the

Northern Cod (Gadus morhua) stock in NAFO Divisions 2J3KL in 2016. DFO Can. Sci. Advis. Sec. Res. Doc. 2018/018. v + 107p

Casini, M., Hjelm, J., Molinero, J. C., Lövgren, J., Cardinale, M., Bartolino, V., Belgrano, A. and Kornilovs, G. 2009. Trophic cascades promote threshold-like shifts in pelagic marine ecosystems. P. Natl. Acad. Sci. 106(1): 197-202.

Clark, D. S., and Emberley, J. 2009. Assessment of Cod in Division 4X in 2008. DFO, Can. Sci. Advis. Sec. Res. Doc. 2009/018. vi + 101 p.

Clausen, L. W., Rindorf, A., Van Deurs, M., Dickey-Collas, M., and Hintzen, N. T. 2018. Shifts in North Sea forage fish productivity and potential fisheries yield. Journal of Applied Ecology, 55(3), 1092-1101. 
DFO. 2016. Assessment of Atlantic cod (Gadus morhua) in the southern Gulf of St.

Lawrence (NAFO Div. 4T-4Vn (Nov. - April)) to 2014. DFO Can. Sci. Advis. Sec. Sci.

Advis. Rep. 2015/061.

Drinkwater, K. F., Miles, M., Medhaug, I., Otterå, O. H., Kristiansen, T., Sundby, S., and Gao, Y. 2014. The Atlantic Multidecadal Oscillation: Its manifestations and impacts with special emphasis on the Atlantic region north of 60 N. Journal of Marine Systems, 133, 117130.

Fogarty, M. J., Myers, R. A., and Bowen, K. G. 2001. Recruitment of cod and haddock in the North Atlantic: a comparative analysis. ICES J. Mar. Sci. 58(5): 952-961.

Gilbert, D. J. 1997. Towards a new recruitment paradigm for fish stocks. Can. J. Fish. Aquat. Sci. 54(4): 969-977.

González-Troncoso, D. 2015. Assessment of the Cod Stock in NAFO Division 3M. NAFO SCR Doc. 15/033.

Holt, R. D., 1977. Predation, apparent competition, and the structure of prey communities. Theor. Popul. Biol. 12(2): 197-229.

Hurrell, J. W. 1995. Decadal trends in the North Atlantic oscillation. Science 269: 676-679.

ICES 2011. Report of the Working Group on Multispecies Assessment Methods (WGSAM), 10-14 October 2011, Woods Hole, USA. ICES CM 2011/SSGSUE:10. Available from www.ices.dk.

ICES. 2013a. Report of the Baltic Fisheries Assessment Working Group. ICES CM 2011/ACOM:10. 843 pp. Available from www.ices.dk.

ICES. 2013b. Report of the Arctic Fisheries Working Group. ICES CM 2013/ACOM:05. 733pp. Available from www.ices.dk.

ICES 2017a. Interim Report of the Working Group on Multispecies Assessment Methods (WGSAM). ICES CM 2017/SSGEPI:20 Available from www.ices.dk. 
ICES 2017b. Report of the Arctic Fisheries Working Group (AFWG). ICES CM 2017/ACOM:06. Available from www.ices.dk.

ICES 2017c. Report of the Working Group on Assessment of Demersal Stocks in the North Sea and Skagerrak (WGNSSK). ICES CM 2017/ACOM:21. Available from www.ices.dk. ICES 2017d. Report of the North Western Working Group (NWWG) ICES CM 2017/ACOM:08. Available from www.ices.dk.

ICES 2017e. Report of the Working Group on Celtic Seas Ecoregion (WGCSE) ICES CM 2017/ACOM:13. Available from www.ices.dk.

Johnson, K. F., Councill, E., Thorson, J. T., Brooks, E., Methot, R. D., and Punt, A. E. 2016.

Can autocorrelated recruitment be estimated using integrated assessment models and how does it affect population forecasts? Fish. Res. 183: 222-232.

Kikkert, A. H. 1993. Analysis of the cod samples collected in the North Sea during the 1991 international stomach sampling project. ICES CM 1993/G:13. Available from www.ices.dk. Kjesbu, O.S., Bogstad, B., Devine, J.A., Gjøsæter, H., Howell, D., Ingvaldsen, R.B., Nash, R.D.M., and Skjæraasen, J.E. 2014. Synergies between climate and management for Atlantic cod fisheries at high latitudes. P. Natl. Acad. Sci. 111(9): 3478-3483.

DOI:10.1073/pnas.1316342111

Madsen, H. 2007. Time series analysis. Chapman \& Hall, pp. 400.

Mantzouni, I., and MacKenzie, B. R. 2010. Productivity responses of a widespread marine piscivore, Gadus morhua, to oceanic thermal extremes and trends. P. R. Soc. Lond. B. Bio. 277(1689): 1867-1874.

McCullaugh, P., and Nelder, J.A. 1989. Generalized linear models. Monogr. Statist. Appl. Probab. No. 37. 
Mohn, R.K., and Rowe, S. 2012. Recovery Potential Assessment for the Laurentian South Unit of Atlantic Cod (Gadus morhua): The Eastern Scotian Shelf Cod Stock (NAFO Div. 4VsW). DFO Can. Sci. Advis. Sec. Res. Doc. 2011/138: viii + 71p.

Morgan, M. J., and G. R. Lilly. 2006. The impact of condition on reproduction in Flemish Cap cod. J. Northw. Atl. Fish. Sci. 37: 81-86. doi: 10.2960/J.v37.m560

NCAR, 2018. International Comprehensive Ocean-Atmosphere Data Set (ICOADS) Release 3, Monthly Summaries. Research Data Archive at the National Center for Atmospheric Research, Computational and Information Systems Laboratory. https://doi.org/10.5065/D6V40SFD. Accessed Oct. 112018.

Northeast Fisheries Science Center. 2013. 55th Northeast Regional Stock Assessment Workshop (55th SAW) Assessment Report. US Dept Commer, Northeast Fish Sci Cent Ref Doc. 13-11; 845 p. Available from: National Marine Fisheries Service, 166 Water Street, Woods Hole, MA 02543-1026, or online at http://www.nefsc.noaa.gov/nefsc/publications/ Punt, A. E., Butterworth, D. S., de Moor, C. L., De Oliveira, J. A., and Haddon, M. 2016. Management strategy evaluation: best practices. Fish Fish. 17: 303-334.

Rideout, R. M., Ings, D.W. and Brattey, J. 2017. An Assessment of the Cod Stock in NAFO Divisions 3NO. NAFO SCR Doc. No. 17/042

Rideout, R.M., Ings, D.W., Healey, B.P., Brattey, J., Morgan, M.J., Maddock Parsons, D., Koen-Alonso, M., and Vigneau, J. 2016. Assessing the status of the cod (Gadus morhua) stock in NAFO Subdivision 3Ps in 2015. DFO Can. Sci. Advis. Sec. Res. Doc. 2016/048 vi + $90 \mathrm{p}$

Ricard, D., Zimmermann, F., and Heino, M. 2016. Are negative intra-specific interactions important for recruitment dynamics? A case study of Atlantic fish stocks. Mar. Ecol. Progr. Ser. 547: 211-217. 
511 SAS Institute Inc. 2017. SAS version 9.4 [computer program]. SAS Institute Inc., Cary, 512 North Carolina.

513 Skjæraasen, J. E., Nash, R. D., Korsbrekke, K., Fonn, M., Nilsen, T., Kennedy, J., Nedreaas, 514 K. H., Thorsen, A., Witthames, P. R., Geffen, A. J., Høie, H. and Kjesbu, O. S. 2012. 515 Frequent skipped spawning in the world's largest cod population. P. Natl. Acad. Sci. 109(23): 516 8995-8999. doi.org/10.1073/pnas.1200223109

517 Spencer, P. D., and Collie, J. S. 1997. Patterns of population variability in marine fish stocks. 518 Fish. Oceanogr., 6: 188-204.

519 Sundby, S. 2000. Recruitment of Atlantic cod stocks in relation to temperature and advectlon 520 of copepod populations. Sarsia, 85: 277-298.

521 Szuwalski, C.S., Vert-Pre, K.A., Punt, A.E., Branch, T.A. and Hilborn, R., 2015. Examining 522 common assumptions about recruitment: a meta-analysis of recruitment dynamics for 523 worldwide marine fisheries. Fish Fish., 16(4): 633-648.

524 Thorson, J. T., Jensen, O. P. and Zipkin, E. F. 2014. How variable is recruitment for 525 exploited marine fishes? A hierarchical model for testing life history theory. Can. J. Fish. 526 Aquat. Sci. 71(7): 973-983.

527 Yaragina, N.A., Høie, H., Koloskova, V.P., Mjanger, H., Nedreaas, K.H., Senneset, H., 528 Zuykova, N. V. and Ågotnes, P. 2011. Precision of the Northeast Arctic cod age 529 determination under variable environmental and information conditions. Marine Biology 530 Research, 7(6), 599-607. 


\section{Tables}

532 Table 1. Summary of expected autocorrelations and cyclic patterns under each of the 533 examined hypotheses.

\begin{tabular}{|c|c|c|c|c|}
\hline $\mathrm{H}$ & Description & $\begin{array}{l}\text { Positive auto- } \\
\text { correlation at lag } \\
1 \text { ? }\end{array}$ & $\begin{array}{l}\text { Negative auto- } \\
\text { correlations? }\end{array}$ & Cycling patterns? \\
\hline 1 & $\begin{array}{l}\text { There are no significant cyclic } \\
\text { patterns in cod recruitment success }\end{array}$ & No & No & White noise \\
\hline 2 & $\begin{array}{l}\text { Recruitment of cod is linked to } \\
\text { annual or decadal climatic variation }\end{array}$ & $\begin{array}{l}\text { Annual effect: } \\
\text { None after } \\
\text { accounting for } \\
\text { effect of } \\
\text { temperature } \\
\text { Decadal effect: } \\
\text { Yes }\end{array}$ & $\begin{array}{l}\text { Annual effect: } \\
\text { None after } \\
\text { accounting for } \\
\text { effect of } \\
\text { temperature } \\
\text { Decadal effect: } \\
\text { No }\end{array}$ & $\begin{array}{l}\text { Annual effect: None } \\
\text { after accounting for } \\
\text { effect of } \\
\text { temperature } \\
\text { Decadal effect: } \\
\text { Decadal wavelength } \\
\text { In all stocks }\end{array}$ \\
\hline 3 & $\begin{array}{l}\text { Cyclic patterns in somatic growth } \\
\text { causes cyclic patterns in offspring } \\
\text { quality }\end{array}$ & $\begin{array}{l}\text { None when } \\
\text { accounting for } \\
\text { effect of weight } \\
\text { at age in } \\
\text { analyses }\end{array}$ & $\begin{array}{l}\text { None when } \\
\text { accounting for } \\
\text { effect of weight at } \\
\text { age in analyses }\end{array}$ & $\begin{array}{l}\text { Residuals from the } \\
\text { weight-recruitment } \\
\text { success relationship } \\
\text { show no cyclic } \\
\text { patterns }\end{array}$ \\
\hline 4 & $\begin{array}{l}\text { The link between recruitment and the } \\
\text { subsequent SSB causes negative } \\
\text { autocorrelations in recruitment } \\
\text { success at some lags. }\end{array}$ & No & $\begin{array}{l}\text { At the age } \\
\text { corresponding to } \\
\text { age at } 50 \% \\
\text { maturity }\end{array}$ & $\begin{array}{l}\text { Wavelength of } \\
2 * \text { age at } 50 \% \\
\text { maturity }\end{array}$ \\
\hline 5 & $\begin{array}{l}\text { A large year class dilutes the } \\
\text { predation mortality of year classes of } \\
\text { a similar weight causing positive }\end{array}$ & $\begin{array}{l}\text { Yes, can occur } \\
\text { for slow growing } \\
\text { stocks at more }\end{array}$ & No & $\begin{array}{l}\text { Significant cyclic } \\
\text { patterns for slow } \\
\text { growing stocks but }\end{array}$ \\
\hline
\end{tabular}




\begin{tabular}{|c|c|c|c|c|}
\hline & $\begin{array}{l}\text { autocorrelation in slow growing } \\
\text { stocks }\end{array}$ & $\begin{array}{l}\text { lags than fast } \\
\text { growing stocks }\end{array}$ & & $\begin{array}{l}\text { not for fast growing } \\
\text { stocks }\end{array}$ \\
\hline 6 & $\begin{array}{l}\text { A large year class reduces the } \\
\text { resources available for the following } \\
\text { year class causing negative } \\
\text { autocorrelation in slow growing } \\
\text { stocks }\end{array}$ & No & Yes & $\begin{array}{l}\text { Wavelength } \\
\text { decreases with } \\
\text { increasing weight at } \\
\text { a specific age }\end{array}$ \\
\hline 7 & Cycles are introduced by cannibalism & $\mathrm{No}^{*}$ & Yes & $\begin{array}{l}\text { Wavelength } \\
\text { decreases with } \\
\text { increasing weight at } \\
\text { a specific age }\end{array}$ \\
\hline
\end{tabular}
will occur. 
538 Table 2.

539 Summary of population data used.

\begin{tabular}{|c|c|c|c|c|}
\hline Stock & Area & & ears & Reference \\
\hline cod-4tvn & S Gulf of St. Lawrence (4TVn) & 1950 & -2014 & DFO 2016 \\
\hline cod-3pn4rs & N Gulf of St. Lawrence (3Pn4RS) & 1974 & -2015 & Brassard et al. 2016 \\
\hline $\operatorname{cod}-2 \mathrm{j} 3 \mathrm{kl}$ & N Newfoundland (2J3KL) & 1983 & -2015 & Brattey et al. 2018 \\
\hline cod-arct & NE Arctic (I, II) & 1946 & -2016 & ICES $2017 \mathrm{~b}$ \\
\hline cod-3no & Grand bank (3NO) & 1959 & - 2017 & Rideout et al. 2017 \\
\hline cod-3ps & S Newfoundland (3Ps) & 1983 & -2016 & Rideout et al. 2016 \\
\hline $\operatorname{cod}-2532$ & E Baltic (IIId -east) & 1966 & - 2012 & ICES 2013a \\
\hline cod-4vsw & E Scotian Shelf (4VsW) & 1958 & -2008 & Mohn and Rowe 2012 \\
\hline $\operatorname{cod}-3 m$ & Flemish Cap (3M) & 1972 & - 2014 & González-Troncoso 2015 \\
\hline cod-ice & Iceland (Va) & 1955 & -2016 & ICES 2017d \\
\hline cod-coas & Norwegian Coastal (IIa) & 1984 & - 2004 & ICES 2013b \\
\hline $\operatorname{cod}-2224$ & W Baltic (IIId -west) & 1970 & -2005 & ICES 2013a \\
\hline $\operatorname{cod}-4 x$ & W Scotian Shelf (4X) & 1980 & - 2007 & Clark and Emberley 2009 \\
\hline cod-gom & Gulf of Maine (5Y) & 1982 & -2010 & Northeast Fisheries Science Center 2013 \\
\hline cod-kat & Kattegat (IIIa -east) & 1971 & -2010 & ICES 2013a \\
\hline cod-farp & Faroe Plateau $(\mathrm{Vb})$ & 1961 & - 2012 & ICES 2017d \\
\hline cod-gb & Georges Bank (5Z) & 1978 & -2010 & Northeast Fisheries Science Center 2013 \\
\hline $\operatorname{cod}-347 d^{*}$ & North Sea (IIIa-IV-VIId) & 1974 & -2016 & ICES 2017c \\
\hline cod-6a & W Scotland (VIa) & 1981 & - 2016 & ICES 2017e \\
\hline cod-7a & Irish Sea (VIIa) & 1968 & -2016 & ICES $2017 \mathrm{e}$ \\
\hline cod-7e-k & Celtic Sea (VIIe-k) & 1971 & -2016 & ICES $2017 \mathrm{e}$ \\
\hline
\end{tabular}

540 * Only the years from 1974 onwards were used as the natural mortalities for the years 19635411973 are only indicative (ICES 2011). 
Table 3. Summary of results. White noise test, autocorrelation at lag 1 (without correcting for effects of other lags), estimated dominant

wavelength and effects of weight anomaly and temperature on detrended recruitment success. Effects are estimated in models including only one of the variables weight anomaly and temperature at a time as no stock showed significant effects of both variables in combined analyses. Bold indicates significant effects at the $5 \%$ level.

\begin{tabular}{|c|c|c|c|c|c|c|c|c|c|}
\hline \multirow[b]{2}{*}{ Stock } & \multirow[b]{2}{*}{ Area } & \multirow[b]{2}{*}{$\begin{array}{c}\text { Weight } \\
\text { at age } \\
4\end{array}$} & \multicolumn{3}{|c|}{ Recruitment success } & \multicolumn{2}{|c|}{ Weight anomaly } & \multicolumn{2}{|c|}{ Temperature } \\
\hline & & & $\begin{array}{l}\text { Autocorrelatio } \\
\text { n (lag 1) }\end{array}$ & $\begin{array}{c}\text { P(white } \\
\text { noise) }\end{array}$ & Wavelength & $\mathbf{P}$ & Effect & $\mathbf{P}$ & effect \\
\hline cod-4tvn & S Gulf of St. Lawrence (4TVn) & 0.39 & $0.69(<0.0001)$ & $<0.0001$ & 9.5 & 0.3716 & 0.10 & 0.5462 & -0.10 \\
\hline cod-3pn4rs & N Gulf of St. Lawrence (3Pn4RS) & 0.40 & $0.47(0.0351)$ & 0.0057 & 4.9 & 0.0158 & 0.04 & 0.6449 & -0.05 \\
\hline $\operatorname{cod}-2 \mathrm{j} 3 \mathrm{kl}$ & N Newfoundland (2J3KL) & 0.53 & $0.80(0.0006)$ & $<0.0001$ & 7.2 & $<0.0001$ & 2.30 & 0.6659 & 0.13 \\
\hline cod-arct & NE Arctic (I, II) & 0.68 & $0.40(0.0007)$ & $<0.0001$ & 3.3 & 0.0003 & -0.38 & 0.1438 & 0.29 \\
\hline cod-3no & Grand bank (3NO) & 0.68 & $0.60(<0.0001)$ & $<0.0001$ & 9.2 & 0.7158 & 0.71 & 0.9185 & 0.02 \\
\hline cod-3ps & S Newfoundland (3Ps) & 0.76 & $0.48(0.0116)$ & 0.0274 & 4.7 & 0.4401 & -0.20 & 0.8298 & 0.03 \\
\hline $\operatorname{cod}-2532$ & E Baltic (IIId -east) & 0.95 & $0.65(<0.0001)$ & $<0.0001$ & 10.7 & 0.3805 & 0.11 & 0.8060 & 0.01 \\
\hline cod-4vsw & E Scotian Shelf (4VsW) & 1.02 & $0.59(<0.0001)$ & 0.0003 & 12.2 & 0.3214 & 0.15 & 0.9167 & 0.01 \\
\hline
\end{tabular}




\begin{tabular}{|c|c|c|c|c|c|c|c|c|}
\hline $\operatorname{cod}-3 m$ & Flemish Cap (3M) & 1.34 & $0.42(0.0039)$ & 0.0065 & 10.0 & 0.1100 & 0.76 & 0.6736 \\
\hline cod-ice & Iceland (Va) & 1.43 & $0.21(0.0951)$ & 0.1106 & 4.3 & 0.0012 & -0.33 & 0.3558 \\
\hline cod-2224 & W Baltic (IIId -west) & 1.60 & $-0.15(0.4377)$ & 0.5537 & 1.5 & 0.1435 & 0.33 & 0.1412 \\
\hline cod-coas & Norwegian Coastal (IIa) & 1.60 & $0.59(0.0024)$ & 0.0044 & 6.2 & 0.4546 & -0.08 & 0.6119 \\
\hline $\operatorname{cod}-4 x$ & W Scotian Shelf (4X) & 1.82 & $-0.33(0.1002)$ & 0.3311 & 1.2 & 0.5975 & -0.31 & 0.3313 \\
\hline cod-gom & Gulf of Maine (5Y) & 2.03 & $0.09(0.6116)$ & 0.1827 & 4.5 & 0.9416 & 0.02 & 0.9093 \\
\hline cod-kat & Kattegat (IIIa -east) & 2.06 & $-0.47(0.0024)$ & 0.0203 & 1.2 & 0.6866 & -0.05 & 0.3685 \\
\hline cod-farp & Faroe Plateau (Vb) & 2.51 & $0.51(<0.0001)$ & $<0.0001$ & 4.0 & $<0.0001$ & -1.03 & 0.8387 \\
\hline cod-gb & Georges Bank (5Z) & 2.73 & $0.10(0.4711)$ & 0.0317 & 5.2 & 0.1167 & -0.28 & 0.5029 \\
\hline $\operatorname{cod}-347 d^{*}$ & North Sea (3a-4-7d) & 3.98 & $-0.18(0.2685)$ & 0.2714 & $1.3^{* *}$ & 0.4113 & 0.12 & 0.0038 \\
\hline cod-6a & W Scotland (6a) & 4.44 & $-0.13(0.4223)$ & 0.3242 & 1.3 & 0.0816 & -0.26 & 0.8567 \\
\hline cod-7a & Irish Sea (7a) & 5.51 & $0.12(0.4260)$ & 0.2752 & $1.0^{* *}$ & 0.1543 & 0.32 & 0.0001 \\
\hline cod-7e-k & Celtic Sea (VIIe-k) & 7.18 & $0.18(0.2267)$ & 0.2416 & $2.2^{* *}$ & 0.9343 & 0.02 & 0.0129 \\
\hline
\end{tabular}

$546 *$ Only the years from 1974 onwards were used as the natural mortalities for the years 1963-1973 are only indicative (ICES 2011).

$547{ }^{* *}$ Based on residuals from the relationship with annual temperature. 
Table 4. Parameters in reduced autoregressive model. All parameters are given so negative parameters correspond to negative autocorrelation 550 and positive parameters to positive autocorrelation.

\begin{tabular}{|c|c|c|c|c|c|c|c|c|c|c|c|}
\hline \multirow[t]{2}{*}{ Stock } & \multirow[t]{2}{*}{ Area } & Lag & Lag & Lag & Lag & Lag & Lag & Lag & Lag & Lag & \multirow[t]{2}{*}{ Lag 10} \\
\hline & & 1 & 2 & 3 & 4 & 5 & 6 & 7 & 8 & 9 & \\
\hline \multirow[t]{2}{*}{ cod-4tvn } & S Gulf of St. Lawrence (4TVn) & 0.64 & & & & & & & & -0.20 & \\
\hline & N Gulf of St. Lawrence & & & & & & & & & & \\
\hline cod-3pn4rs & (3Pn4RS) & 0.43 & & & -0.39 & & & & & & \\
\hline $\operatorname{cod}-2 \mathrm{j} 3 \mathrm{kl}$ & N Newfoundland (2J3KL) & 1.23 & -0.54 & & & & & & & & \\
\hline cod-arct & NE Arctic (I, II) & 0.34 & & -0.51 & & & & -0.22 & & & \\
\hline cod-3no & Grand bank (3NO) & 0.62 & & & & & -0.43 & 0.29 & & & \\
\hline cod-3ps & S Newfoundland (3Ps) & & & & & & & & & & \\
\hline $\operatorname{cod}-2532$ & E Baltic (IIId -east) & 0.93 & -0.45 & & & & & & & & \\
\hline cod-4vsw & E Scotian Shelf (4VsW) & 0.44 & & & & & & & & -0.44 & \\
\hline $\operatorname{cod}-3 m$ & Flemish Cap (3M) & 0.37 & & & & & & & & & -0.39 \\
\hline cod-ice & Iceland (Va) & & & & -0.28 & & & & & & \\
\hline cod-2224 & W Baltic (IIId -west) & & & & & & & & & & \\
\hline
\end{tabular}




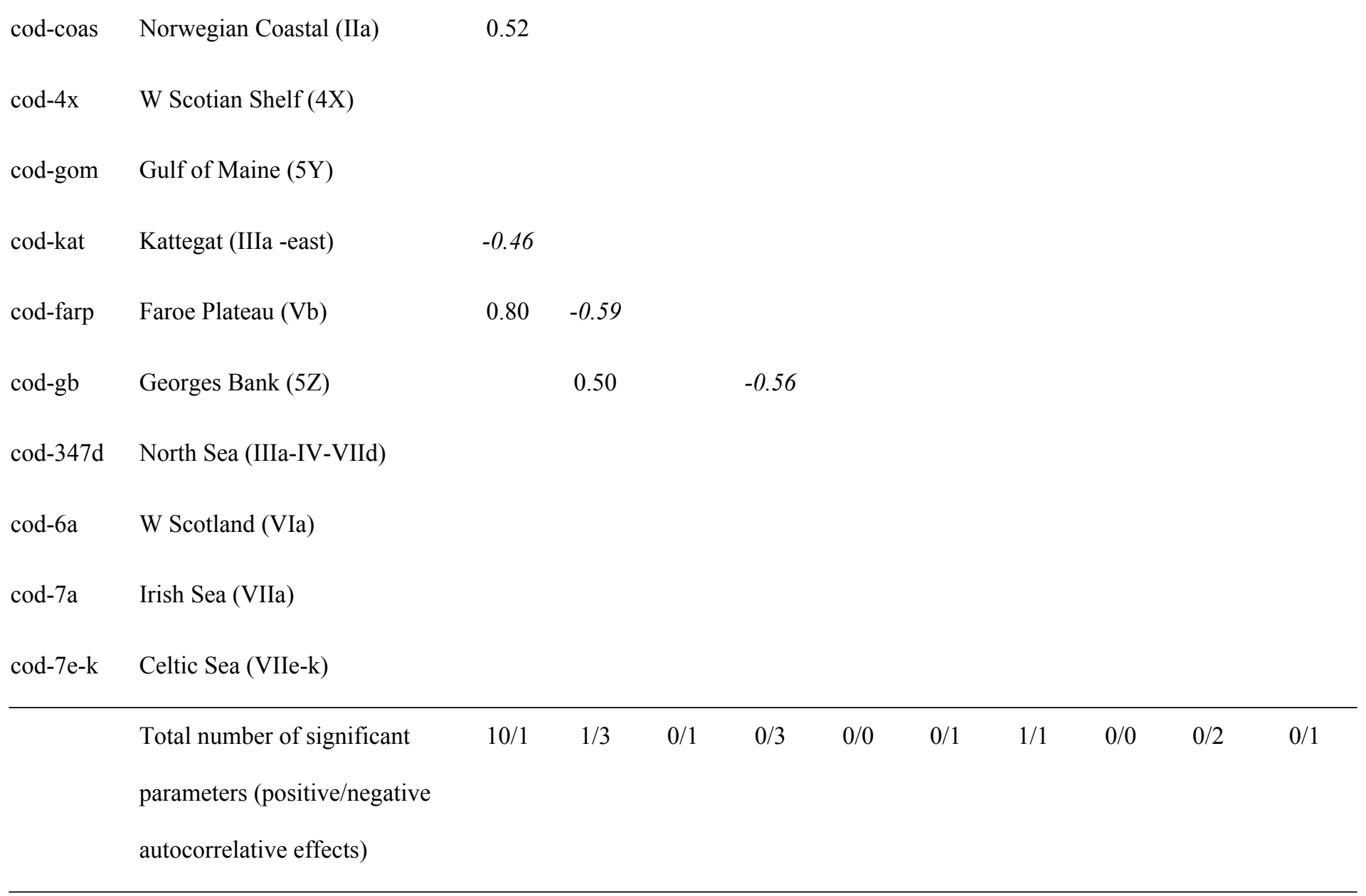




\section{Captions}

553 Fig. 1. Examples of time series showing both long term change and shorter term cycles. Panel a shows two observed time series (solid and broken black), the long term trend (dotted grey) estimated by different polynomial orders corresponding to 20 (linear) and 30 (quadratic) and years of data fitted to the broken line time series and the true trend (dash-dot). Panel b shows the detrended time series and the wavelength defined as the number of years between successive peaks (arrows on top in panel b). Panel c shows the autocorrelation at different lags of the two cycles, the short wavelength (solid line in panels a and b) is shown as filled columns, the long wavelength (dashed line in panels a and b) as open columns. and 0.0015 , respectively). line), recruitment success (middle panel, solid line is observation and broken line is polynomial fit) and detrended recruitment success (right panel) of selected stocks. Year indicates the year 
576 intermediate wavelength (Iceland cod, cod-ice, d, e and f), high wavelength (Grand Banks cod, 577 cod-no, g, h and I and Northern Newfoundland cod, j, k and 1).

578

579 Fig 4. Relationship between the dominant wavelength of recruitment success and age at 50\%

580 maturity (a), weight at age 4 (b) and between autocorrelation at lag 1 and weight at age 4 (c).

581 Lines are regressions using all periodicities (linear for a, logarithmic for $\mathrm{c}$ and d). Filled

582 symbols denote significant periodicity and autocorrelations.

583

584 Fig. 5. Observed autocorrelations of stocks ordered according to increasing weight at age 4.

585 Colour of bars indicate weight at age 4 : white $<1.5 \mathrm{~kg}$, grey $1.5-3 \mathrm{~kg}$, black $>3 \mathrm{~kg}$. Stars indicate 586 where lags are significant at the $5 \%$ level in a reduced autoregressive model with lags up to 10 . 


\section{$1 \quad$ Figures}
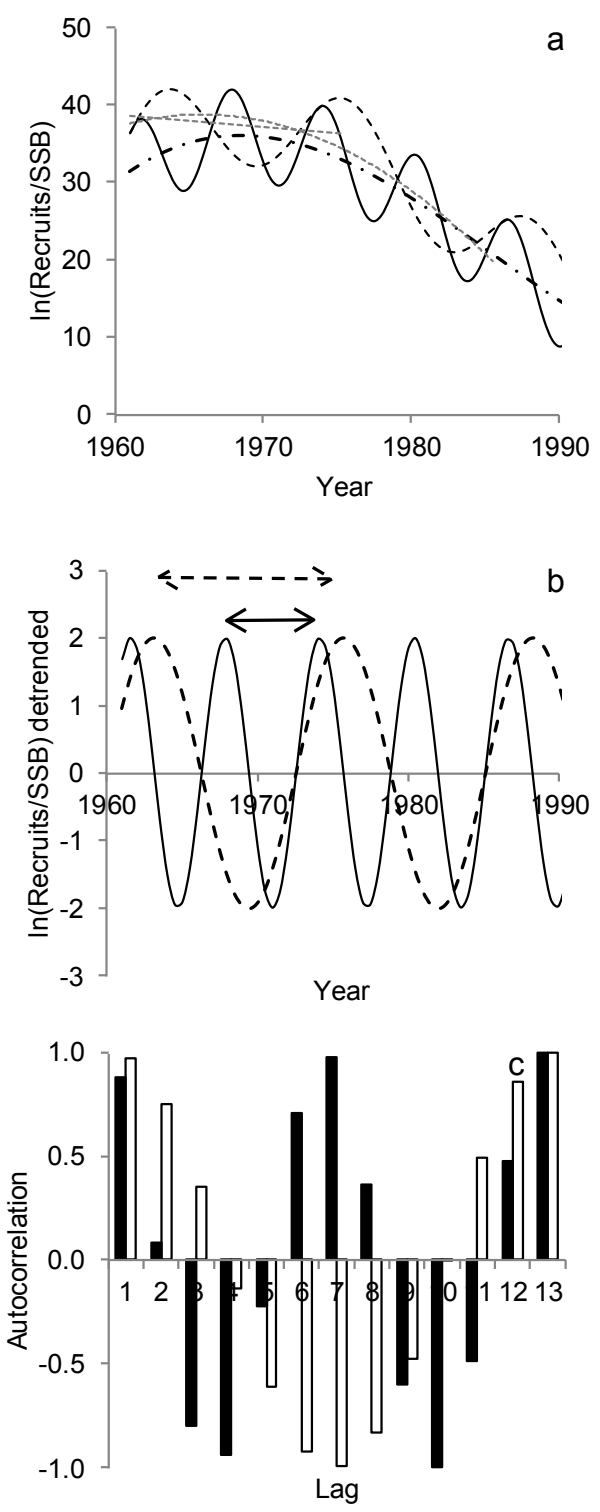

3 Fig. 1. Examples of time series showing both long term change and shorter term cycles. Panel a

4 shows two observed time series (solid and broken black), the long term trend (dotted grey)

5 estimated by different polynomial orders corresponding to 20 (linear) and 30 (quadratic) and years

6 of data fitted to the broken line time series and the true trend (dash-dot). Panel $b$ shows the 
7 detrended time series and the wavelength defined as the number of years between successive peaks

8 (arrows on top in panel b). Panel c shows the autocorrelation at different lags of the two cycles, the

9 short wavelength (solid line in panels $a$ and $b$ ) is shown as filled columns, the long wavelength

10 (dashed line in panels a and $b$ ) as open columns. 


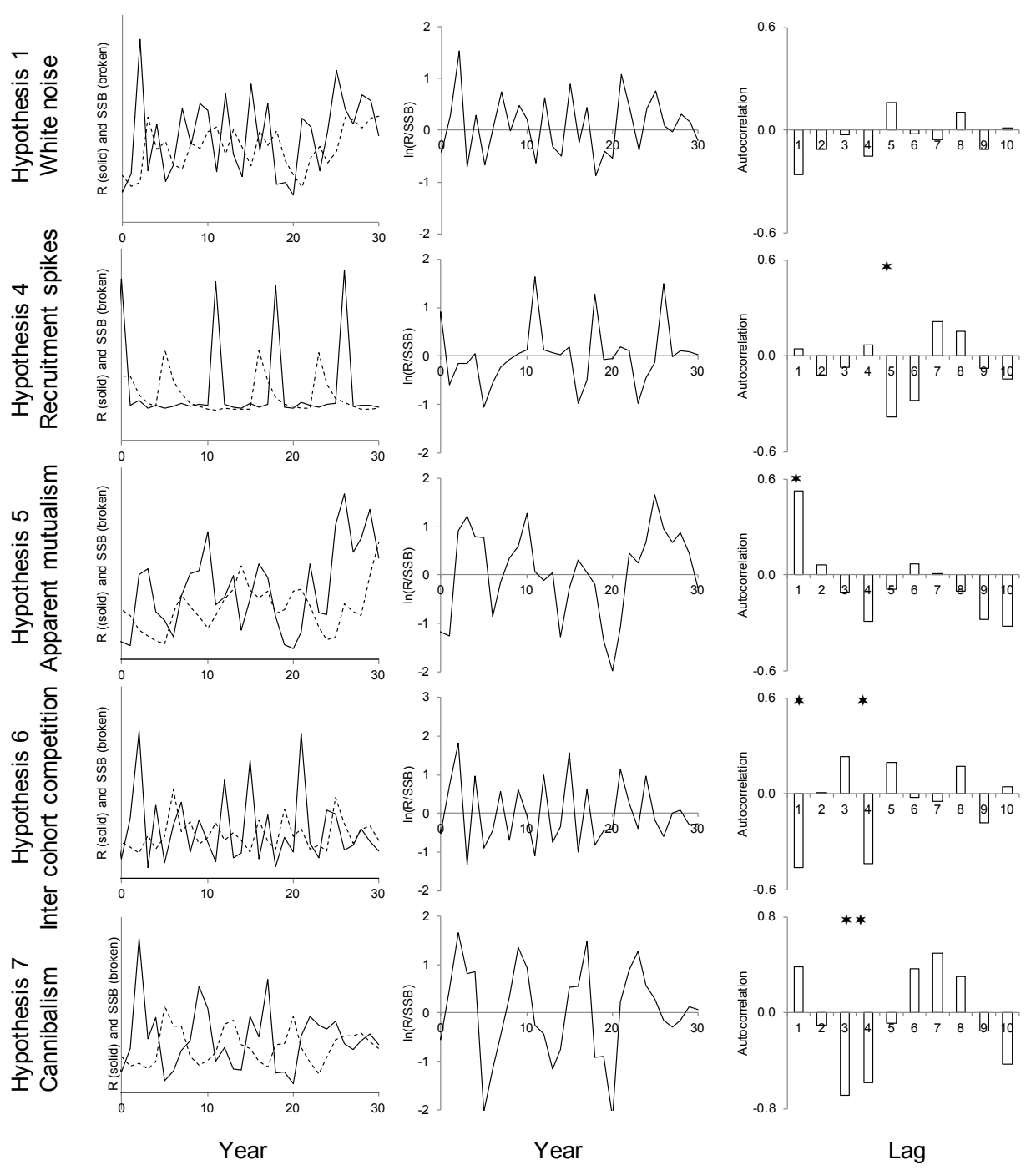

Fig. 2. Examples of development of recruitment (solid line, left panel) and spawning stock biomass

14 (broken line, left panel), $\ln (\mathrm{R} / \mathrm{SSSB})$ (middle panel) and autocorrelation (right panel) under each 15 hypothesis 1 and 4-7. Hypotheses 2 and 3 would result in significant effects of temperature (2) or 16 growth (3) on recruitment success, but accounting for these effects in the detrending of the time series 17 would lead to periodicities in detrended $\ln (\mathrm{R} / \mathrm{SSSB})$ similar to results for hypothesis 1 . Hypotheses 1 18 and 4 are not significantly different from white noise $(P>0.6000)$, though hypothesis 4 shows 
19

20
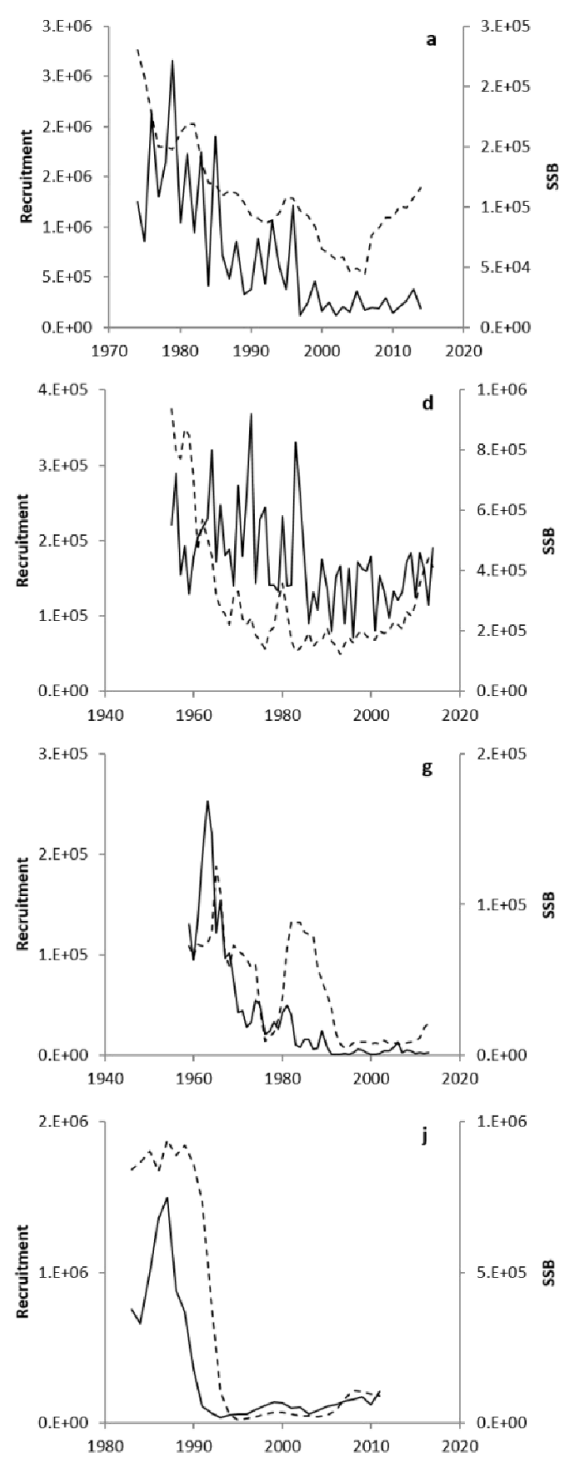

21

22

23

24

significant autocorrelation at lag 5 (the age at maturity). Hypotheses 5 to 7 are all significantly different from white noise ( $P=0.0007,0.0144$ and 0.0015 , respectively).
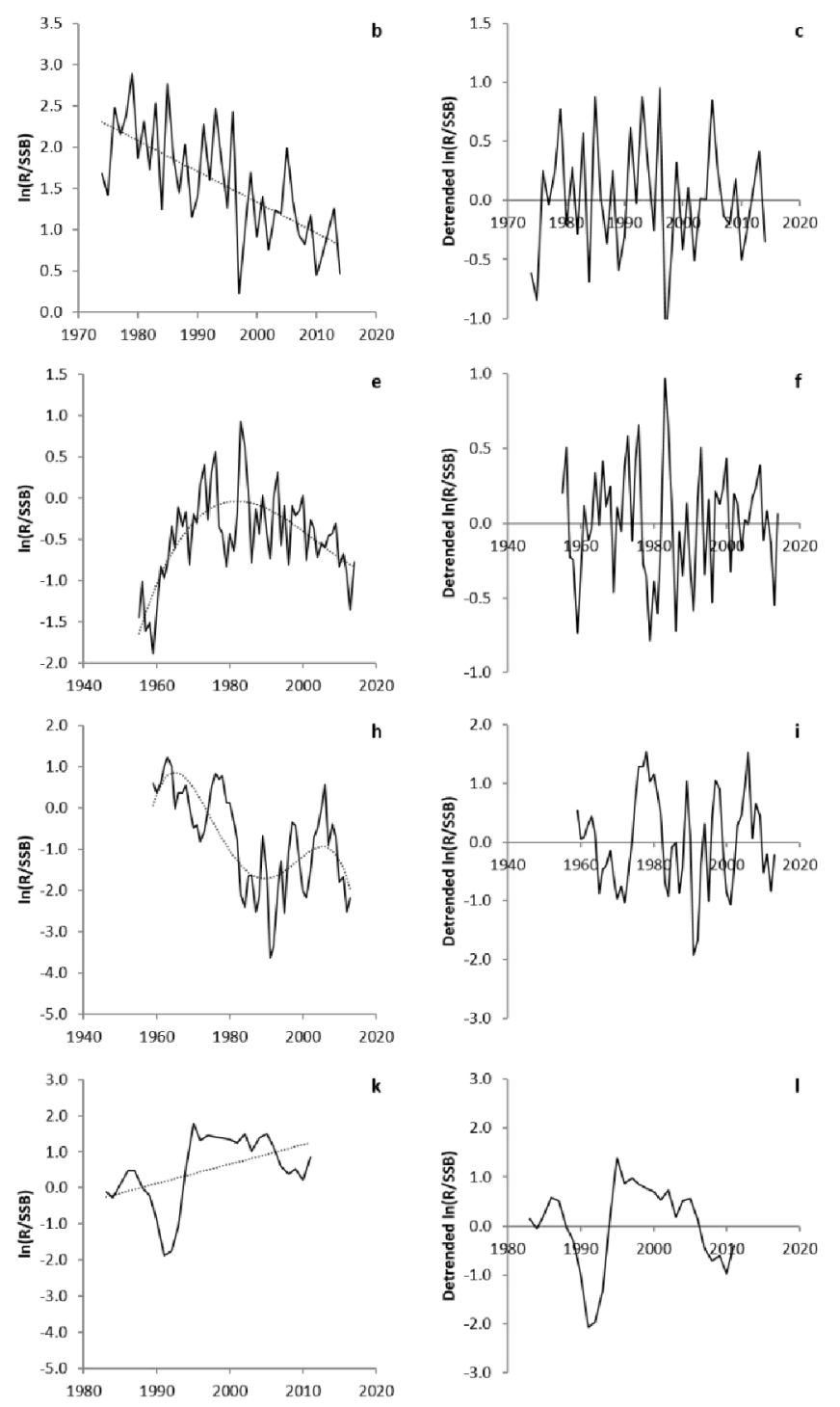

Year

Fig 3. Time series of recruitment (thousands, left panel, solid line), SSB (left panel, broken line), recruitment success (middle panel, solid line is observation and broken line is polynomial fit) and 
detrended recruitment success (right panel) of selected stocks. Year indicates the year the cohort was spawned. Examples of low wavelength (North Sea, cod-347d, a, b and c), intermediate wavelength (Iceland cod, cod-ice, d, e and f), high wavelength (Grand Banks cod, cod-no, g, h and I and Northern Newfoundland cod, $\mathrm{j}, \mathrm{k}$ and I).
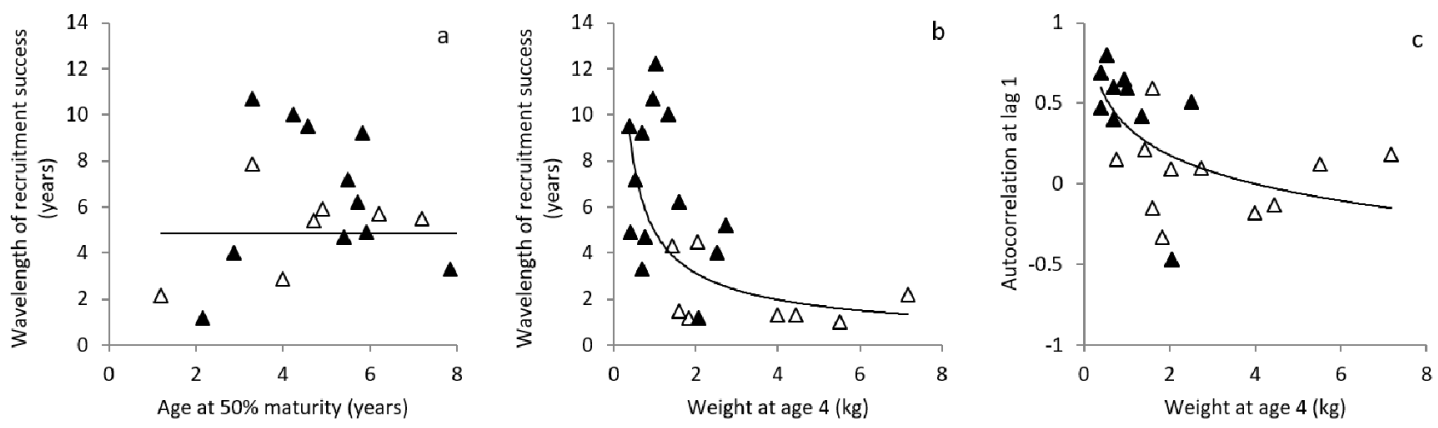

Fig 4. Relationship between the dominant wavelength of recruitment success and age at $50 \%$

maturity (a), weight at age 4 (b) and between autocorrelation at lag 1 and weight at age 4 (c). Lines are regressions using all periodicities (linear for a, logarithmic for $\mathrm{c}$ and d). Filled symbols denote significant periodicity and autocorrelations. 


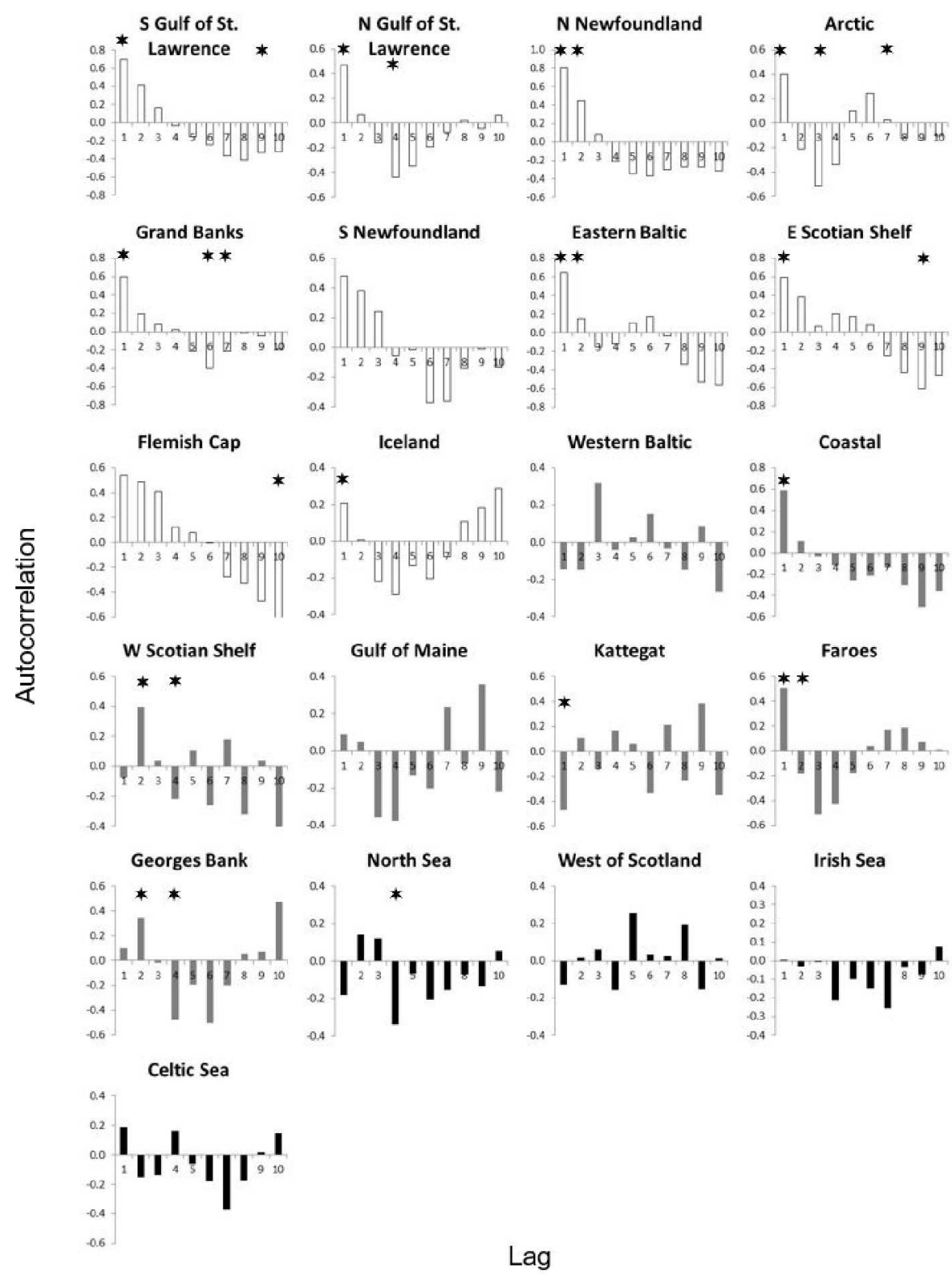

Fig. 5. Observed autocorrelations of stocks ordered according to increasing weight at age 4 . Colour of bars indicate weight at age 4 : white $<1.5 \mathrm{~kg}$, grey $1.5-3 \mathrm{~kg}$, black $>3 \mathrm{~kg}$. Stars indicate where lags are significant at the $5 \%$ level in a reduced autoregressive model with lags up to 10 . 